\title{
Monitoring the course of early-age reactions in alkali activated aluminosilicates
}

\author{
Miloš Jerman ${ }^{1, *}$, Vratislav Tydlitát ${ }^{1}$, and Robert Černý $^{1}$ \\ ${ }^{1}$ Czech Technical University in Prague, Faculty of Civil Engineering, Department of Materials \\ Engineering and Chemistry, 16629 Prague, Czech Republic
}

\begin{abstract}
In this paper the reaction heat development of alkali activated aluminosilicates is studied by an isothermal heat flow calorimeter. The highest reaction activity is observed during two hours after mixing. The hydration heat power at early time is influenced mainly by the composition of tested mixtures involving ceramic dust as precursor and different amounts of sodium hydroxide and water glass as activators and by temperature.
\end{abstract}

\section{Introduction}

Alkali-activated aluminosilicates (AAA) can be utilized as alternative binders due to their low environmental impact. The chemical process to form AAA involves two steps: (i) Dissolution of raw materials in alkali activator to form $\mathrm{Si}$ and $\mathrm{Al}$ gel on the materials surface, (ii) Polycondensation to form networked polymeric oxide structure.

Among the aluminosilicate sources solid wastes or industrial by-products can be utilized. Frequently used and studied is a fly ash, other frequently used materials are blast furnace slag, metakaolin, or ceramic dust powder. As an alkali activator $\mathrm{NaOH}, \mathrm{KOH}$ or water glass is often used. The concentration level and type of the activator play an important role in the mechanical and microstructural properties of resultant AAA. Binary AAA system composed of waste ceramic dust and metakaolin was tested by Rovnaník et al. [1]. A synergic effect between metakaolin and ceramic powder was shown. Another binary system composed of fly ash and slag was tested by Jang et al. [2]. Higher contents of slag increased the compressive strength of alkali-activated fly ash/slag pastes but caused rapid setting and crack appearance due to autogeneous shrinkage [2].

The final properties of AAA are influenced by chemical composition of precursors and activators and by curing conditions. Thermal curing has a positive effect on compressive strength [3]. Initial curing at $25{ }^{\circ} \mathrm{C}$ does not though lead in some cases to formation of reaction products and at least the curing temperatures of $40{ }^{\circ} \mathrm{C}$ and higher are necessary [4].

In this paper, the reaction heat development of several AAA with different silicate modulus of the activator was tested. Ceramic dust was activated by sodium hydroxide or by a combination of sodium hydroxide and water glass.

* Corresponding author: milos.jerman@,fsv.cvut.cz 


\section{Materials and samples}

The ceramic dust was delivered by Heluz v.o.s.. Parameters of ceramic dust were determined in our previous works aimed at its application in cement- and lime-based composites $[5,6]$. The chemical composition has been identified by XRF analysis, the amorphous part of the composition was determined by a combination of XRF and X-ray diffraction analysis. The results are given in Table 1 . The density of ceramic dust was 2615 $\mathrm{kg} \cdot \mathrm{m}^{-3}$, its specific surface $1374 \mathrm{~m}^{2} \mathrm{~kg}^{-1}$, the grain size distribution was very fine, with $\mathrm{d}_{50}=8.1 \mu \mathrm{m}$.

The composition of studied alkali activated aluminosilicates, which was designed by Prof. Pavla Rovnaníková from the Faculty of Civil Engineering, Brno University of Technology, is presented in Table 2. Silicate modulus was calculated as the molar ratio of $\mathrm{SiO}_{2} / \mathrm{Na}_{2} \mathrm{O}$. The silicate modulus of the sodium water glass was $1.6, \mathrm{NaOH}$ was in its pure form.

Table 1. Composition of ceramic dust

\begin{tabular}{|l|l|l|l|l|l|l|l|l|l|}
\hline & $\mathbf{S i O}_{2}$ & $\mathbf{A l}_{2} \mathbf{O}_{3}$ & $\mathbf{F e}_{2} \mathbf{O}_{3}$ & $\mathbf{C a O}$ & $\mathbf{M g O}$ & $\mathbf{K}_{2} \mathbf{O}$ & $\mathbf{N a}_{\mathbf{2}} \mathbf{O}$ & $\mathbf{T i O}_{\mathbf{2}}$ & $\mathbf{S O}_{3}$ \\
\hline Whole ceramic & 51.3 & 20.0 & 6.0 & 11.5 & 4.5 & 3.2 & 1.3 & 0.8 & 1.0 \\
\hline $\begin{array}{l}\text { Amorphous } \\
\text { part }\end{array}$ & 24.4 & 33.7 & 7.1 & 19.0 & 7.9 & 2.3 & 1.1. & 1.5 & 1.2 \\
\hline
\end{tabular}

Table 2. Composition of studied geopolymer mixtures

\begin{tabular}{|c|c|c|c|c|c|}
\hline Mixture & $\begin{array}{c}\text { Ceramic dust } \\
{[\mathrm{g}]}\end{array}$ & $\begin{array}{c}\text { Water glass1,6 } \\
{[\mathrm{g}]}\end{array}$ & $\begin{array}{c}\mathrm{NaOH} \\
{[\mathrm{g}]}\end{array}$ & $\begin{array}{c}\text { Water } \\
{[\mathrm{ml}]}\end{array}$ & $\begin{array}{c}\text { Silicate } \\
\text { modulus }\end{array}$ \\
\hline FH-K120 & 200 & 70 & 15.57 & 50 & 0.8 \\
\hline FH-K121 & 200 & 70 & 9.5 & 50 & 1.0 \\
\hline FH-K123 & 200 & 70 & 2.57 & 50 & 1.4 \\
\hline FH-K105 & 200 & 80 & 2.95 & 36 & 1.4 \\
\hline FH-K108 & 200 & 90 & 3.33 & 31 & 1.4 \\
\hline
\end{tabular}

\section{Experimental methods}

The isothermal heat flow calorimeter KC 01 [7] was applied for the measurement of hydration heat development in the analyzed alkali activated aluminosilicates. The device is based on the differential measurement of heat flow. Detectors for the heat flow measurement are constructed in the form of copper-constantan thermocouple columns, which are wound up on an insulator plate. The thermocouple joints are placed on the edges of the plate and glued to a copper tube which a cylinder copper reaction vessel with the specimen of about 1-2 $\mathrm{g}$ is inserted into. The detectors on the tube where the hydration process takes place are connected differentially with the detectors for determination of heat flow at the reference vessel where no hydration processes occur. The vessels and detectors are arranged in an axial symmetric way. Data collection is performed using the datalogger MS 2 (Comet) with the signal detection range of $0-100 \mathrm{mV}$ and sensitivity of $0.01 \mathrm{mV}$. The collected data is then transferred from the datalogger to PC and processed. In the measurement of temperature inside the calorimeter a resistance thermometer Almemo (Ahlborn) with the sensitivity of $0.01{ }^{\circ} \mathrm{C}$ is used.

The calibration of the $\mathrm{KC} 01$ calorimeter was carried out on the Joule heat principle, using a resistor with the precisely known resistance of $9.99 \mathrm{k} \Omega$ placed into the reaction 
vessel and powered by regulated DC power supply. The voltage was measured by a highaccuracy digital voltmeter. In the range of 0 to $100 \mathrm{mV}$, the applied power was found to be proportional to output voltage of the differentially arranged thermocouple columns, with the calibration constant of $16.00 \mathrm{~mW} / \mathrm{mV}$ at $25^{\circ} \mathrm{C}, 18.71 \mathrm{~mW} / \mathrm{mV}$ at $40{ }^{\circ} \mathrm{C}$.

The measurement was performed with a $1 \mathrm{~g}$ sample of ceramic dust in a cylindrical copper vessel of inner diameter $8.25 \mathrm{~mm}$ and height $70 \mathrm{~mm}$, with a tight rubber plug.

Before the experiment, the ceramic was weighted, placed into the vessel. The sodium hydroxide and water glass were mixed with water. After 24 hours the liquid component was used for measurement. A weighted syringe with a mix of water and liquid chemical admixtures has been placed near the reaction vessel, and so was a plastic tubule intended for paste mixing. The calorimeter with the solid sample and liquid components was left to stabilize the temperature. After about $2 \mathrm{~h}$ stabilization, the calorimeter was opened and liquid components were inserted into the vessel. The paste was mixed for $30 \mathrm{~s}$ by rotation of the plastic tubule mixer, then the vessel was closed by a rubber plug. The calorimeter was closed by two aluminum lids. Each experiment was performed for $40 \mathrm{~h}$.

\section{Experimental results}

The specific hydration heat power of all mixtures tested at $25{ }^{\circ} \mathrm{C}$ is shown in Figure 1. and for temperature $40{ }^{\circ} \mathrm{C}$ in Figure 2. The maximum for both cases corresponding to the dissolution occurred three minutes after mixing the solid components with liquid. For both cases the highest specific hydration heat power achieved mixtures with higher silicate modulus. However, this peak was influenced also by the wetting heat. In the later times the specific hydration heat power for all AAA slowly decreased and any other peak did not occur for both cases of curing.

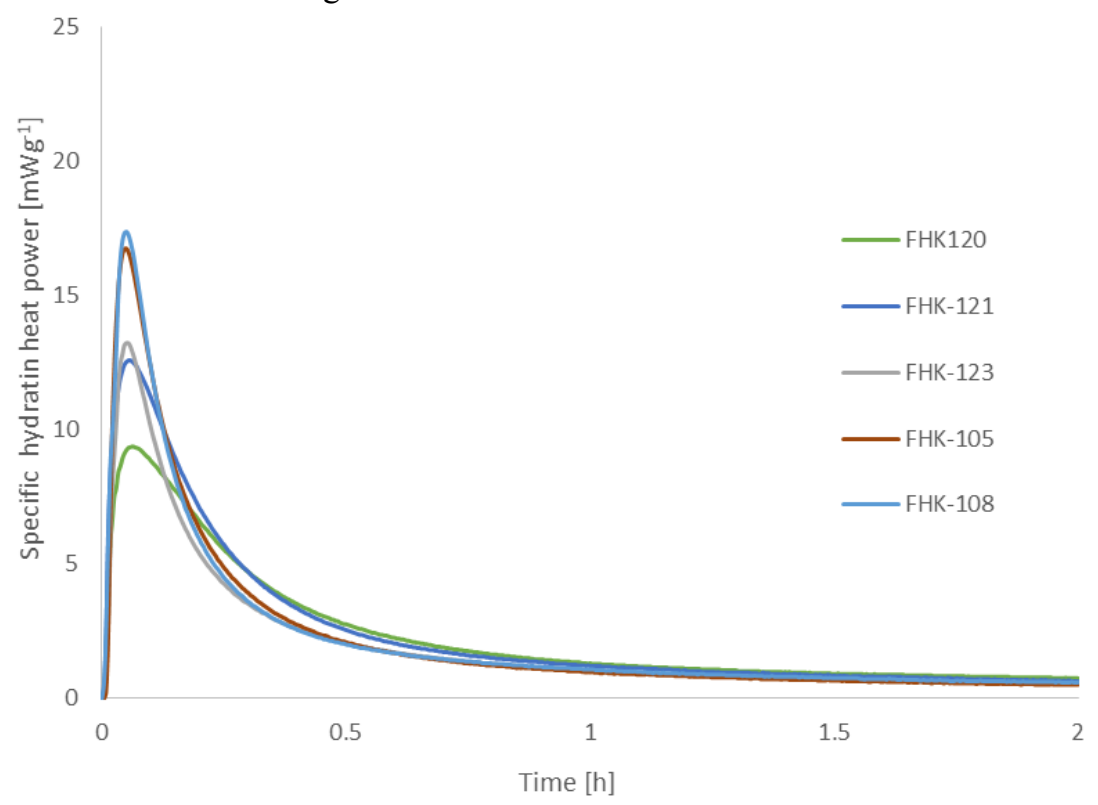

Fig. 1. Specific hydration heat power measured under isothermal conditions at $25^{\circ} \mathrm{C}$. 


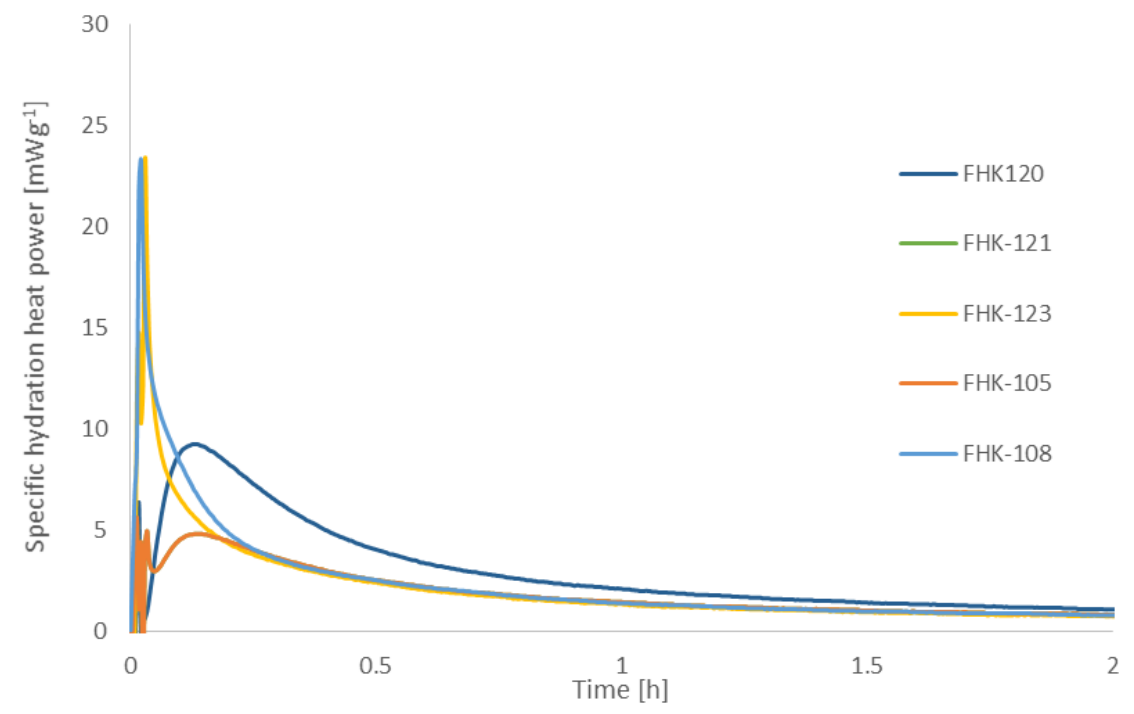

Fig. 2. Specific hydration heat power measured under isothermal conditions at $40{ }^{\circ} \mathrm{C}$.

The specific hydration heat for the curing temperature of $25{ }^{\circ} \mathrm{C}$ is shown in Fig. 3, for $40{ }^{\circ} \mathrm{C}$ in Fig. 4. For the higher curing temperature a higher amount of specific hydration heat was achieved for all mixtures. The hydration process was, apparently, accelerated at higher temperature.

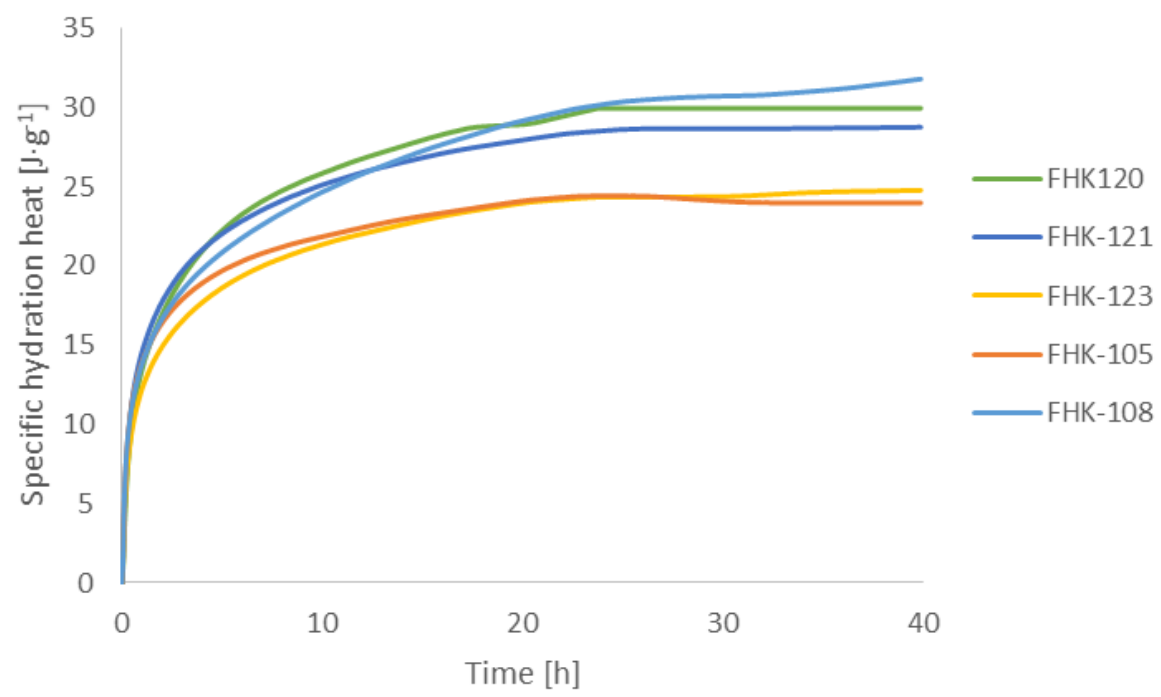

Fig. 3. Specific hydration heat measured under isothermal conditions at $25^{\circ} \mathrm{C}$. 
At the curing temperature of $25{ }^{\circ} \mathrm{C}$ the highest specific hydration heat after 40 hours achieved mixtures with highest and lowest silicate modulus, FHK108 and FHK120. For the curing temperature of $40{ }^{\circ} \mathrm{C}$ the highest specific hydration heat achieved the mixture with lowest silicate modulus FHK120. It should be noted that the specific hydration heat values measured in this paper were about two times lower than, e.g., in the case of AAA based on fly ash and slag [2].

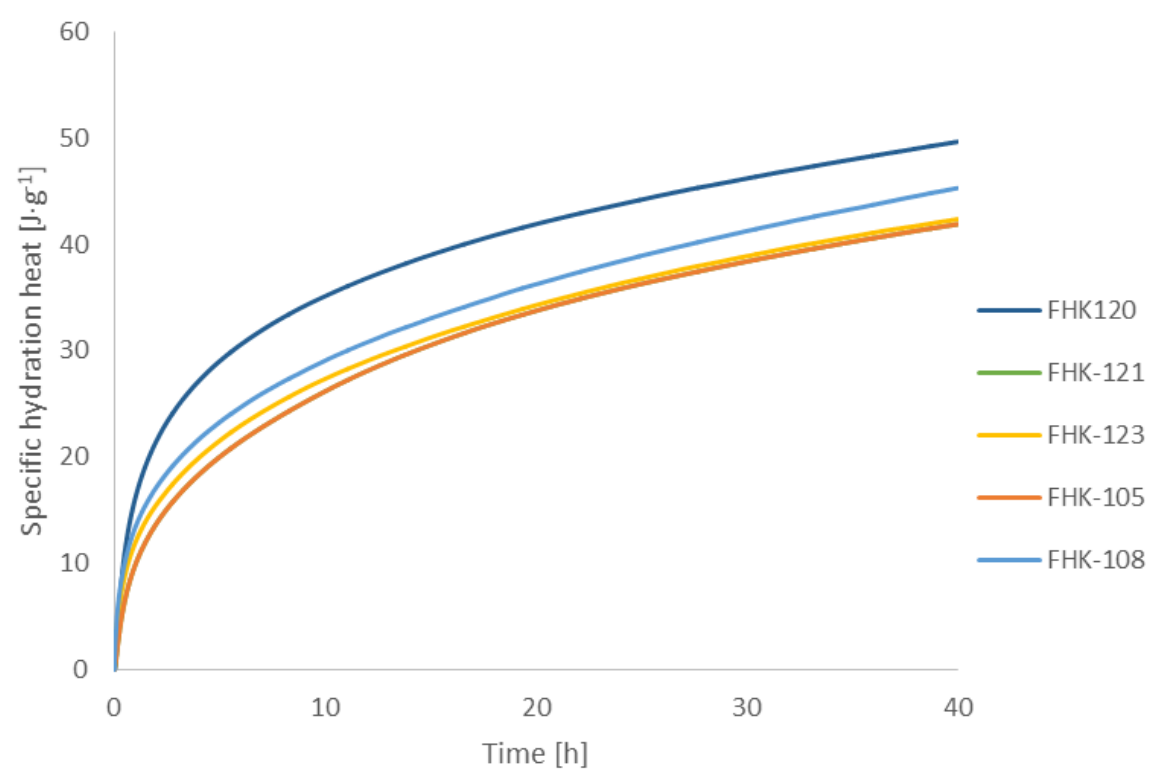

Fig. 4. Specific hydration heat measured under isothermal conditions at $40{ }^{\circ} \mathrm{C}$.

\section{Conclusions}

The effect of curing conditions (temperature) and amount of alkaline activator in the AAA based on ceramic dust on the hydration heat development was investigated. Hydration processes were analyzed using isothermal heat flow calorimetry at $25^{\circ} \mathrm{C}$ and $40{ }^{\circ} \mathrm{C}$. In both cases the specific hydration heat power vs. time curve exhibited only one peak which reflected mainly the dissolution of ceramic dust in the alkaline environment. The results showed that at higher curing temperature the specific hydration heat was increased and the polycondensation process was accelerated. The effect of silicate modulus of the activator was not very pronounced within the range of 0.8 to 1.4 .

This research has been supported by the Czech Science Foundation, under project No 19-01982S.

\section{References}

1. P. Rovnaník, P. Rovnaníková, M. Vyšvařil, S. Grzeszczyk, E. Janowska-Renkas, Constr. Build. Mater. 188, 924-933, (2018)

2. J.G. Jang, N.K. Lee, H.K. Lee, Constr. Build. Mater. 50, 169-176 (2014)

3. D. Nasr, A.H. Pakshir, H. Ghayour, Constr. Build. Mater. 190, 108-119, (2018) 
4. G.V.P. Bhagath Singh, Kolluru V.L. Subramaniam, Cem. Concr. Compos., 95, 10-18 (2019)

5. M. Jerman, V. Tydlitát, M. Keppert, M. Čáchová, R. Černý, Thermochimica Acta 633, 108-115 (2016)

6. V. Kočí, J. Kočí, M. Čáchová, E. Vejmelková, R. Černý, Composites Part B 93, 184189 (2016)

7. V. Tydlitát, P. Tesárek, R. Černý, Journal of Thermal Analysis and Calorimetry 91, 791-796 (2008) 